\title{
Using Ferrous Ion for the Reductive Degradation of Hexavalent Chromium
}

\author{
Jude O. Ighere, Karina Honjoya, Ramesh C. Chawla \\ Chemical Engineering Department, Howard University, Washington DC, USA \\ Email: rchawla@howard.edu
}

Received 25 October 2014; revised 26 November 2014; accepted 25 December 2014

Copyright (C) 2015 by authors and Scientific Research Publishing Inc.

This work is licensed under the Creative Commons Attribution International License (CC BY). http://creativecommons.org/licenses/by/4.0/

(c) (i) Open Access

\section{Abstract}

This paper discusses the toxicity and mobility of chromium species. And it presents the extent and kinetics of reductive remediation of hexavalent chromium, $\mathrm{Cr}^{+}$using ferrous ion, $\mathrm{Fe}^{2+}$. Molar ratios of 1:3 and 1:6 of $\mathrm{Cr}$ (VI) to Fe (II) were used. Integral method of data analysis showed reaction followed second-order kinetics with $R$ square values near unity. Reaction was initially fast but with a rapid precipitation attributed to $\mathrm{Cr}$ (III)-Fe (III) in previous studies. This colloidal precipitate ultimately stops the reaction, which explains while conversion efficiency increases with increased molar ratio of $\mathrm{Cr}$ (VI) to $\mathrm{Fe}$ (II). The impact of $\mathrm{pH}$ was investigated by adjusting the $\mathrm{Cr}$ (VI)-Fe (II) medium to $\mathrm{pH} 2.78,5.24,7.00,9.00$ and 11.96 using predetermined drops of acid or base. Reaction was more rapid under alkaline conditions with higher extent of degradation consistent with previous research. In soil system, mass transfer limitation was hardly noticed as high extent of reduction was recorded relative to aqueous phase. The high solubility of $\mathrm{Cr}$ (VI) aided the release into the aqueous media for reduction by ferrous sulfate.

\section{Keywords}

Reduction, Hexavalent, Trivalent Chromium, Remediation, Degradation, Ferrous Ion, Kinetics

\section{Introduction}

\subsection{Background}

Chromium is lustrous and does not tarnish in air and water like other metals such as copper and aluminum. These properties have been exploited by different industries including alloy manufacturing, leather tanning, corrosion control, wood polishing, ink production, metal finishing, electroplating, textiles and chemical manufacture [1]. These industrial applications have contributed to the rise in chromium contamination. Toxic Release Inventory (TRI) reported that in 2009, the total chromium released into the environment (soil, water and air) 
from industrial processes amounted to 36,385,312 pounds/year (Tri09 2011). Chromium was also the major corrosion control species used at Hanford and Savannah River Nuclear facilities. Cooling water towers and distribution pipes were coated with chromium to minimize fouling. The US EPA has enlisted chromium among the 13 priority pollutant metals (Ag, As, Be, Cd, $\mathrm{Cr}, \mathrm{Cu}, \mathrm{Hg}, \mathrm{Ni}, \mathrm{Pb}, \mathrm{Sb}, \mathrm{Se}, \mathrm{Tl}, \mathrm{Zn}$ ).

Chromium exhibits different oxidation states which are $+1,+3,+4,+5$, and +6 . These oxidation states have been observed to show differences in toxicity, solubility and transport [1]. Among these species, hexavalent chromium (+6) has been reported to be toxic and most probably carcinogenic [2]. Hexavalent chromium has high solubility and hence high mobility in water. These properties contribute to the spread and elevated levels of endangered waters. In December 2010, the Washington Post article reported that tap water in 31 out of 35 major cities contained hexavalent chromium (Cr (VI)) [3]. To reduce chromium contamination and adverse health effects to United States residents, the EPA has set a maximum contaminant level (MCL) of $0.05 \mathrm{mg} / \mathrm{L}$ and $2 \mathrm{mg} / \mathrm{L}$ in surface water for $\mathrm{Cr}$ (VI) and total chromium, respectively [4].

Contrary to hexavalent chromium, $\mathrm{Cr}$ (VI), trivalent chromium, $\mathrm{Cr}$ (III) is non-toxic. Cr (III) is used in low concentrations as micronutrient supplement in foods as it is an essential element required for normal carbohydrate, lipid, and protein metabolism in humans and animals [5] [6]. The low mobility (transport) of $\mathrm{Cr}$ (III) which is attributed to the low solubility of this species in water is also important. The control of proliferated contamination has involved the immobilization of $\mathrm{Cr}$ (VI) by reducing it to $\mathrm{Cr}$ (III).

\subsection{Mobility of Chromium Species}

Hexavalent chromium is transported in flowing groundwater because it is highly soluble in water. The transport of chromium species like other heavy metals naturally depends on interaction with soil. However, the thermodynamic stability of the chromium species depends on the redox potential and $\mathrm{pH}$ of the medium. $\mathrm{Cr}$ (VI) is more stable than $\mathrm{Cr}$ (III) in all $\mathrm{pH}$ range and has higher mobility. Conversely, studies have shown that the sorption of $\mathrm{Cr}$ (III) to soil surface is more likely than $\mathrm{Cr}$ (VI). Hence $\mathrm{Cr}$ (III) is regarded to form complex with soil because of high retention tendency (immobility) in soil [7]. But $\mathrm{Cr}$ (VI) is mostly retained in soil with significant amount of iron $(\mathrm{Fe})$. This phenomenon is still unclear.

This variability evidently impacts the reaction rates, bioavailability and constituted hazard of the chromium species [8]. Some studies have also shown that the mobility of $\mathrm{Cr}$ (III) is facilitated at lower $\mathrm{pH}$ due to the formation of soluble complexes with humus or other organic matter [1]. Obviously, Cr (III) nontoxic, immobile and insoluble properties are directly opposite to the properties of $\mathrm{Cr}$ (VI). Therefore, the design of efficient process to transform $\mathrm{Cr}$ (VI) to $\mathrm{Cr}$ (III) focuses on redox manipulation to detoxify and immobilize chromium contaminants.

\subsection{Cr (VI) Reduction by Fe (II)}

The environmentally beneficial form of chromium is the immobile, nontoxic trivalent chromium. Reduction usually involves the use of reductant or reductant generating material for the purpose of transforming toxic compounds to nontoxic or less toxic ones. However, there are a number of reducing agents such as sulphite, sodium dithionite, hydrogen peroxide and ferrous ion that can be used to achieve this transformation. But ferrous ion has been popularly used possibly because it suites natural environmental process-Fe (II) also is produced through photochemical reactions that occur in sunlit natural waters [9]. Ferrous ion effectively interacts with solid-phase and dissolved-phase $\mathrm{Cr}$ (VI) transforming it to $\mathrm{Cr}$ (III).

Ferrous ion, Fe (II) is oxidized to Fe (III) by releasing the electron while $\mathrm{Cr}$ (VI) is reduced by accepting the electron. Therefore, three moles of Fe (II) are required under ideal conditions to reduce one mole of $\mathrm{Cr}$ (VI) to $\mathrm{Cr}$ (III) as illustrated below (Equations (1)-(3))

$$
\begin{gathered}
\mathrm{F}^{2+} \rightarrow \mathrm{F}^{3+}+\mathrm{e}^{-} \quad\left(\mathrm{E}^{\circ}=-0.77 \mathrm{~V}\right) \\
3 \mathrm{Fe}^{2+} \rightarrow 3 \mathrm{Fe}^{3+}+3 \mathrm{e}^{-} \\
\mathrm{Cr}_{2} \mathrm{O}_{7}^{2-}+14 \mathrm{H}^{+}+6 \mathrm{e}^{-} \rightarrow 2 \mathrm{Cr}^{3+}+7 \mathrm{H}_{2} \mathrm{O}
\end{gathered}
$$

In the dichromate form, $\mathrm{Cr}_{2} \mathrm{O}_{7}^{2-}$, there are two atoms of $\mathrm{Cr}(\mathrm{VI})$. Therefore, six electrons are required to reduce the predominant form of chromium to $\mathrm{Cr}$ (III). In which case six atoms of Fe (II) ions are oxidized to re- 
duce $\mathrm{Cr}(\mathrm{VI})$ in $\mathrm{Cr}_{2} \mathrm{O}_{7}^{2-}$. The above oxidation half-reaction is combined with the reduction half-reaction to give the overall redox reaction (Equation (4)).

$$
\mathrm{Cr}_{2} \mathrm{O}_{7}^{2-}+14 \mathrm{H}^{+}+3 \mathrm{Fe}^{2+}+3 \mathrm{e}^{-} \rightarrow 2 \mathrm{Cr}^{3+}+3 \mathrm{Fe}^{3+}+7 \mathrm{H}_{2} \mathrm{O} \quad\left(\mathrm{E}^{\circ}=-0.423\right)
$$

Using stochiometric ratio (i.e. $\mathrm{Cr}$ (VI):Fe (II) of 1:3), some researchers have modeled the reaction kinetics to be first order with respect to both $\mathrm{Fe}(\mathrm{II})$ and $\mathrm{Cr}$ (VI) respectively but overall second-order reaction [8]:

$$
r=-\frac{\mathrm{d}[\mathrm{Cr}(\mathrm{VI})]}{\mathrm{d} t}=-\frac{\mathrm{d}[\mathrm{Fe}(\mathrm{II})]}{\mathrm{d} t}=k[\mathrm{Cr}(\mathrm{VI})][\mathrm{Fe}(\mathrm{II})]
$$

Recent articles have limited information on the kinetic analysis for this reaction in soil systems possibly due to imposed mass transfer limitations. Speciation of $\mathrm{Fe}^{\mathrm{n}+}$ and $\mathrm{Cr}^{\mathrm{m}+}$ and reaction kinetics under different $\mathrm{pH}$ conditions have been considered by previous studies [8]. The reaction is rapid and accompanied by colloidal precipitates depending on concentrations of reacting constituents and conditions of medium. Therefore, this paper presents the extent and kinetics of $\mathrm{Cr}$ (VI) degradation in aqueous phase using ferrous ions under laboratory conditions. It also gives insight on the extent of reaction in soil system and the impact of $\mathrm{pH}$.

\section{Materials and Methods}

\subsection{Chemical Preparation}

All the chemicals used in this study are reagent grade. The EPA methods 3060A and 7196A were adapted in this study for the alkaline digestion of spiked soil and hexavalent chromium analysis respectively. For alkaline digestion sodium hydroxide $(\mathrm{NaOH})$ solid and sodium carbonate $\left(\mathrm{Na}_{2} \mathrm{CO}_{3}\right)$ solid were purchased from Fischer Scientific, while 1,5-diphenylcarbazide (DPC) and acetone $\left(\left(\mathrm{CH}_{3}\right)_{2} \mathrm{CO}\right.$; 99.5\%) were purchased from Acros Organics, ferrous sulfate, $\mathrm{FeSO}_{4} \cdot 7 \mathrm{H}_{2} \mathrm{O}$ (purchased from Fischer Scientific) stock solutions were prepared by dissolving $\mathrm{FeSO}_{4} \cdot 7 \mathrm{H}_{2} \mathrm{O}$ crystals in Milli-Q deionized water. Following EPA recommendation, the alkaline digestion solution ( $\left.0.28 \mathrm{M} \mathrm{Na}_{2} \mathrm{CO}_{3} / 0.5 \mathrm{M} \mathrm{NaOH}\right)$ was prepared by dissolving $20 \mathrm{~g}$ of $\mathrm{NaOH}$ and $30 \mathrm{~g}$ of anhydrous $\mathrm{Na}_{2} \mathrm{CO}_{3}$ in $1 \mathrm{~L}$ of the Milli-Q ${ }^{\mathrm{TM}}$ deionized water. Following EPA method 7196A, a solution of 1,5-diphenylcarbazide (DPC) was prepared by dissolving $250 \mathrm{mg}$ of DPC in $50 \mathrm{ml}$ of acetone and stored brown bottle away from light and was used for the purple color development for the quantification of UV-VIS analytical results. All stock solutions were stored away from light to prevent any potentials degradation by light.

\subsection{Soil Contamination Procedure}

The soil (Chelsea soil) used in this study is a well characterized soil obtained from Chelsea, Michigan. Chelsea soil was spiked in the laboratory by dissolving $13 \mathrm{~g}$ of potassium dichromate, $\mathrm{K}_{2} \mathrm{Cr}_{2} \mathrm{O}_{7}$ in $500 \mathrm{ml}$ of the Milli$\mathrm{Q}^{\mathrm{TM}}$ deionized water. The $200 \mathrm{ml}$ of prepared solution was added to $100 \mathrm{~g}$ of Chelsea soil in a container and thoroughly mixed. The chromium contaminated soil slurry was allowed to sun dry. Homogenous soil-chromium matrix was obtained by repeated addition of water followed by mixing and drying. The soil was allowed to age for three months and then pulverized. The artificially contaminated soil sample was digested and extracted using EPA methods 3060A. EPA method 7196A was thereafter used to analyze the recovered solution to determine the amount of $\mathrm{Cr}$ (VI) that is retained in soil matrix. The $\mathrm{Cr}$ (VI) was determined to be $23 \pm 1.7 \mathrm{mg} / \mathrm{g}$ in soil. Samples were centrifuged and decanted before analysis to minimize particle interference.

\subsection{Experimental Procedure}

In aqueous phase, predetermined amounts of $\mathrm{K}_{2} \mathrm{Cr}_{2} \mathrm{O}_{7}$ solution was added to $\mathrm{FeSO}_{4}$ solution in $40 \mathrm{ml}$ vials to obtain molar ratios of 1:3 and 1:6 of $\mathrm{Cr}(\mathrm{VI})$ to $\mathrm{Fe}$ (II) in three different sets of experiment. At ambient conditions $\left(\sim 25^{\circ} \mathrm{C}, 1 \mathrm{~atm}\right)$, twelve $40 \mathrm{ml}$ vials per experiment containing the same molar ratio of $\mathrm{K}_{2} \mathrm{Cr}_{2} \mathrm{O}_{7}$ and $\mathrm{FeSO}_{4}$ were used to monitor rate of $\mathrm{Cr}$ (VI) reduction to $\mathrm{Cr}$ (III). The vials placed on a rotary mixer at $50 \mathrm{rpm}$ (Figure 1). At selected time intervals, one reactor (40 ml vials) sample was collected and analyzed using EPA method 7196A for Cr (VI) concentration. A 5000 Cary UV-Vis spectrophotometer was used for Cr (VI) analysis. All experiments were performed in triplicates. The process flow diagram (PFD) of the experimental process and analysis are shown in Figure 1 and Figure 2. 


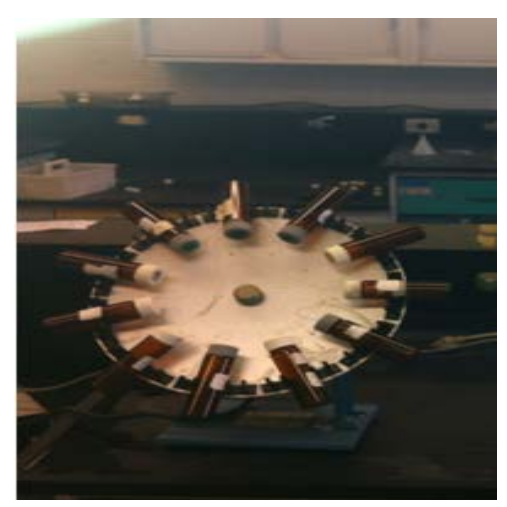

Figure 1. $40 \mathrm{ml}$ vials on rotary mixer.

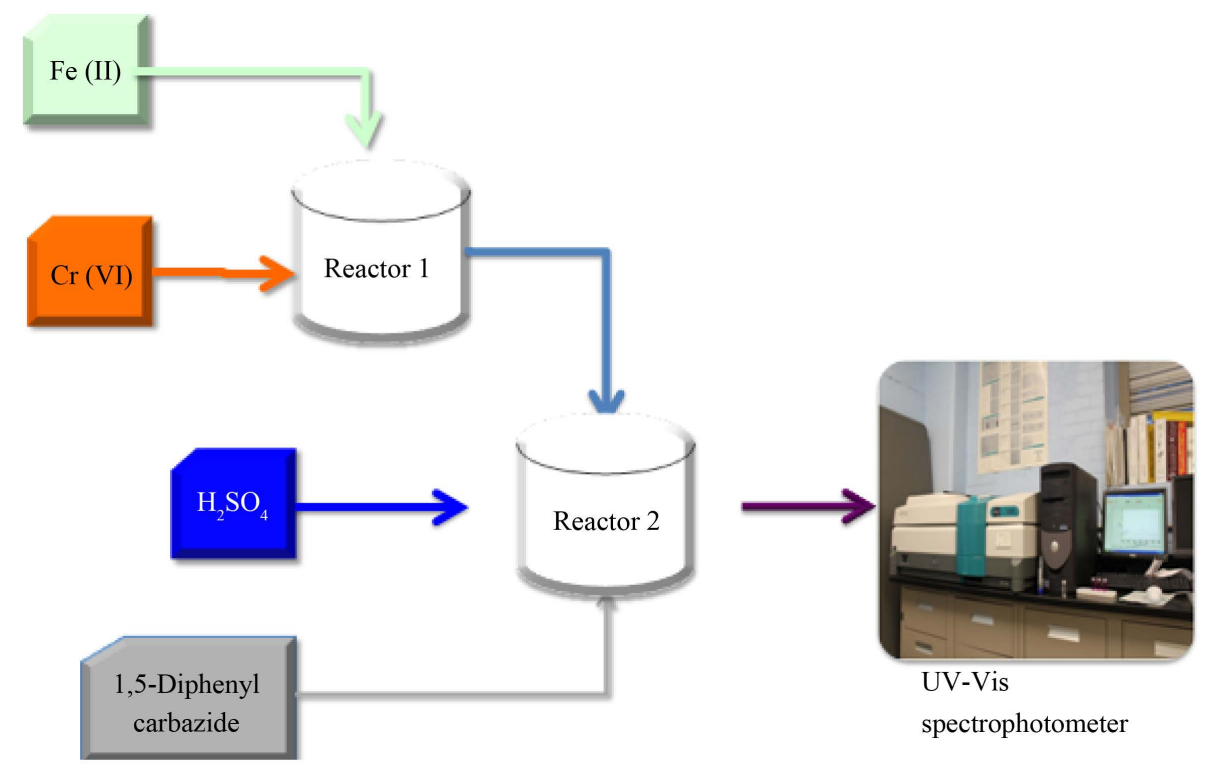

Figure 2. PFD for Cr (VI) reduction in water and analysis.

The described batch experiments above were repeated in soil media using $3 \mathrm{~g}$ of $\mathrm{Cr}$ (VI) spiked soil (artificially contaminated) under the same operating conditions. Ferrous sulfate solution was added to five $40 \mathrm{ml}$ vials each containing $3 \mathrm{~g}$ of $\mathrm{Cr}$ (VI)-contaminated soil. At selected time intervals, samples were centrifuged and the $\mathrm{Cr}$ (VI) in the aqueous phase is analyzed using the EPA Method 7196A. The residue soil was digested by alkaline method using EPA method 3060A to determine the concentration of Cr (VI) retained. The digested soil is centrifuged and the aqueous phase is again analyzed by EPA method 7196A for Cr (VI) analysis. Simultaneous control experiments were conducted using the Cr (VI) contaminated soil samples in Milli-Q de-ionized water in the absence of any ferrous sulfate.

The impact of $\mathrm{pH}$ on the reduction of $\mathrm{Cr}$ (VI) was investigated for $\mathrm{Cr}$ (VI) to Fe (II) in a molar ratio of 1 to 3 only. The $\mathrm{pH}$ of $\mathrm{K}_{2} \mathrm{Cr}_{2} \mathrm{O}_{7}$ solutions in five different vials were adjusted using $\mathrm{H}_{2} \mathrm{SO}_{4}$ and $\mathrm{NaOH}$ solutions to 2.78 , 5.24, 7.00, 9.00 and 11.96. Stochiometric equivalent of Fe (II) solution was added to the individual vials and placed on a rotary mixer. The reaction was allowed to continue for 2 hours based on the predetermined equilibrium time from the kinetic experiments. The concentrations of $\mathrm{Cr}$ (VI) remaining in the sample vials were analyzed using a 5000 Cary UV-Vis spectrophotometer following EPA method 7196A.

\section{Results and Discussion}

\subsection{Extent of Cr (VI) Reduction by $\mathrm{FeSO}_{4}$ in Aqueous Media}

There have been some controversies about the reported rates of Cr (VI) reduction by Fe (II). Some authors have 
reported slow rates of reactions of few minutes [10] [11] while other researchers reported much slower reaction rates in seconds [8] [12] [13]. In this study, the reaction profile shows that the reactions are as fast or slow as particles of ferric ions colloids precipitated. These particles constitute an instant mass transfer limitation. Hence, adapting different methods of analysis would give different reaction rates but similar rate constants.

In this study UV analysis was performed after centrifuging to remove ferric particles. Figure 3 shows the plot obtained for the extent of $\mathrm{Cr}$ (VI) reduction by Fe (II) in molar ratios of 1 to 3 and 1 to 6 of Fe (II) to Cr (VI). Over a 3-hour (180 min) period, at molar ratios of 3 and 6, the conversions were $43.97 \%$ and $81.12 \%$ respectively (see Figure 3). The Cr (VI) reduction reached equilibrium in less than $25 \mathrm{~min}$ of reaction even when excess reducing agent was used. There was no complete degradation even at doubled amount of reducing agent due to rapid precipitation of possible Fe (II)-Cr (III) colloidal particles which is a barrier to further reaction. For complete instantaneous reduction, more than doubled the amount of Fe (II) would be required.

A plot of $\ln [(\mathrm{M}-\mathrm{Xa}) /(\mathrm{M}(1-\mathrm{Xa}))]$ against time was used to analyze the reaction kinetics and the secondorder rate constant. The graph shown in Figure 4, presents a linear correlation as the $R^{2}$ value about unity. According to Buerge and Hug, 1998, the overall reaction is second order and only first order with respect to both contaminants. The second order rate constants were calculated from the slope of the graph (Figure 4). The rate constants obtained were $12.998 \mathrm{mM}^{-1} \cdot \mathrm{s}^{-1}$ and $19.499 \mathrm{mM}^{-1} \cdot \mathrm{s}^{-1}$ for molar ratios of $\mathrm{Cr}$ (VI) to Fe (II) of 1:3 and 1:6 respectively. These rates fall in the range of rates from previous studies between $0.0983 \mathrm{mM}^{-1} \cdot \mathrm{s}^{-1}$ and $2 \times 10^{9}$ $\mathrm{mM}^{-1} \cdot \mathrm{s}^{-1}$. This wide range of previously reported rate constants have been attributed to the different sources of ferrous ion used and other parameters such as ambient conditions, mixing frequency and $\mathrm{pH}$ of media [13] [14].

\subsection{Extent of Cr (VI) Reduction by $\mathrm{FeSO}_{4}$ in Soil Matrix}

In soil medium, further mass transfer resistance is imposed on the reaction. The controlling parameter is also the molar ratios of $\mathrm{Cr}$ (VI) to Fe (II). As in soil system, the reaction is also rapid since Cr (VI) is highly soluble. However, the soil pores are rapidly clogged by the colloid particles of Fe (II)-Cr (III) formed. This rapidly reduces the interface (surface area) for interaction. In this study, at a molar ratio of 1 to 10 and 1 to 15 for $\mathrm{Cr}(\mathrm{VI})$ to Fe (II) a conversion of $73 \%$ and $91.9 \%$ respectively over a 3-hour period. The plots in Figure 5 show that loosely complexed particles of $\mathrm{Cr}(\mathrm{VI})$ to soil matrix are rapidly released from the soil pores into the water phase and are reduced accordingly. Subsequent releases of particles of $\mathrm{Cr}(\mathrm{VI})$ are reduced slowly.

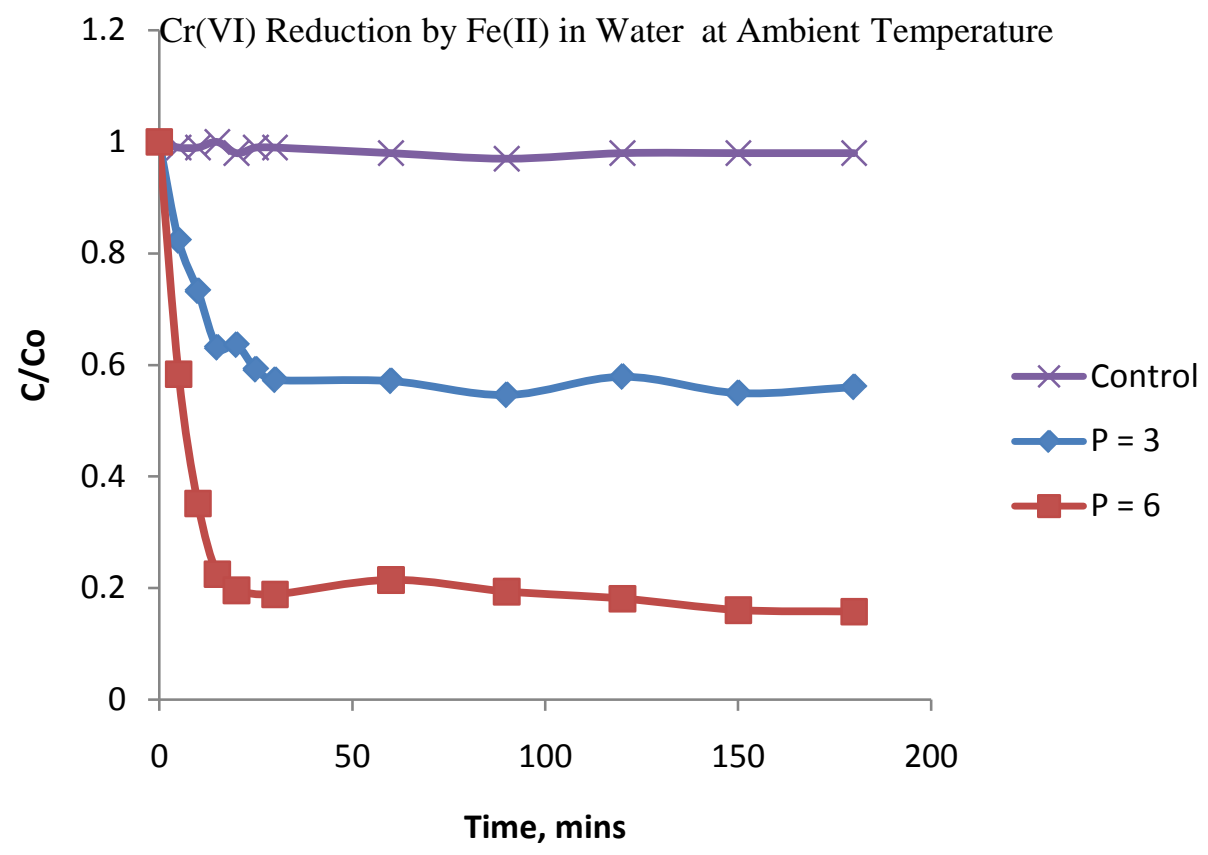

Figure 3. $\mathrm{Cr}(\mathrm{VI})$ reduction by $\mathrm{Fe}(\mathrm{II})$ in water, where $\mathrm{C}=$ concentration of $\mathrm{Cr}$ (VI) at $\mathrm{t}$ and $\mathrm{Co}$ $=$ initial concentration of $\mathrm{Cr}(\mathrm{VI})$. 


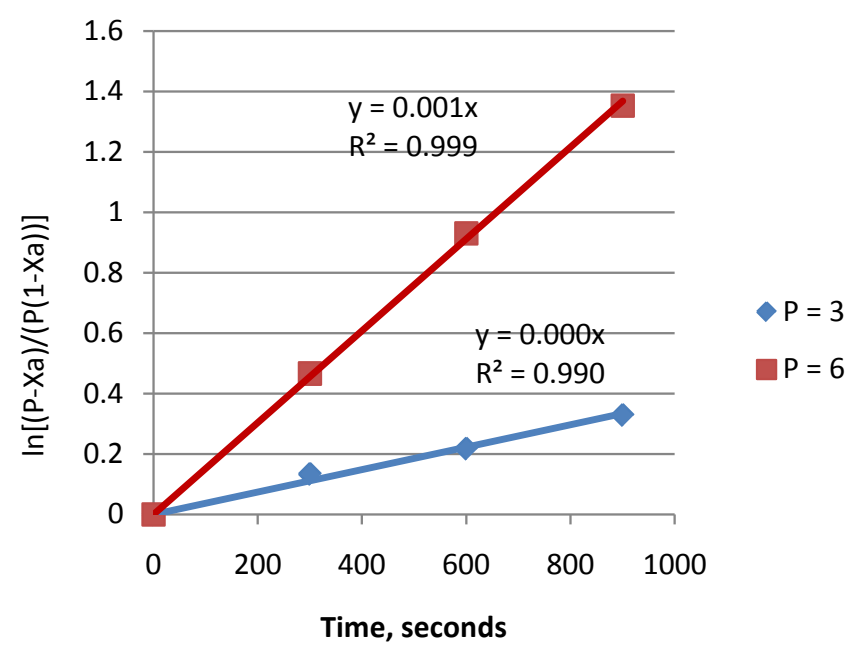

Figure 4. Kinetic analysis of $\mathrm{Cr}$ (VI) reduction by $\mathrm{Fe}$ (II) in aqueous phase.

Reduction of $\mathrm{Cr}(\mathrm{VI})$ to $\mathrm{Cr}(\mathrm{III})$ in Chelsea Soil by Fe(II) at Ambient Temperature

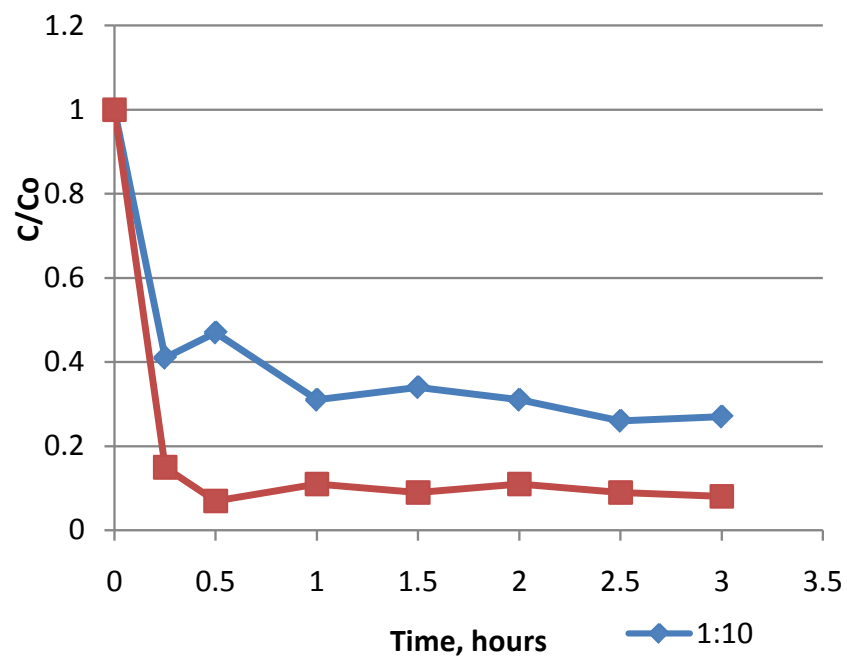

Figure 5. Cr (VI) reduction in Chelsea soil.

\subsection{Impact of $\mathrm{pH}$ on $\mathrm{Cr}$ (VI) Reduction by $\mathrm{FeSO}_{4}$}

Groundwater compositions vary from one contaminated site to another and these to a large extent influences the $\mathrm{pH}$ conditions. Also, soil types and composition vary for different hazardous waste sites. $\mathrm{pH}$ might therefore be a very important parameter in contaminant degradation. While $\mathrm{pH}$ did not largely impact the degradation process, the trend indicates that at alkaline condition the efficiency of $\mathrm{Cr}$ (VI) reduction by $\mathrm{Fe}$ (II) is slightly higher (Figure 6). This result is consistent with some studies that recorded high reaction rates and extent at high alkaline $\mathrm{pH}$ [13] [15]. Schlautman and Han further explained that this can be attributed to the dissolved Fe (II) speciation with $\mathrm{pH}$.

\section{Conclusions}

$\mathrm{Fe}^{2+}$ is a very strong reductant for $\mathrm{Cr}(\mathrm{VI})$ and the reaction is rapid as results indicate both in soil and aqueous system. However, the efficiency of the reaction is immediately controlled by the rapid precipitation of colloids 


\section{Cr(VI) Reduced with $\mathrm{pH}$}

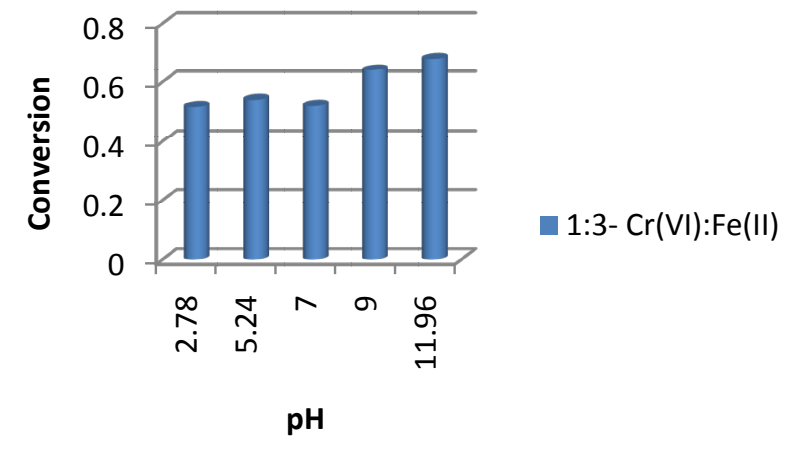

Figure 6. Influence of $\mathrm{pH}$ on $\mathrm{Cr}(\mathrm{VI})$ reduction.

particles which ultimately slows down the reaction. Hence the reaction does not go to completion even in the presence of excess reductant.

The reaction kinetics is similar both in soil and aqueous media but the instantaneous reaction that is rapidly impacted by the accumulation of precipitates. Also, the results indicate that the system performed slightly better under alkaline conditions. Further research is required to determine measures for preventing the accumulation of ferric particles in this reaction.

\section{References}

[1] Avudainayagam, S., Megharaj, M., Owens, G., Kookana, R.S., Chittleborough, D. and Naidu, R. (2003) Chemistry of Chromium in Soils with Emphasis on Tannery Waste Sites. Reviews of Environmental Contamination and Toxicology, 178, 53-91. http://dx.doi.org/10.1007/0-387-21728-2_3

[2] Levankumar, L., Muthukumaran, V. and Gobinath, M.B. (2009) Batch Adsorption and Kinetics of Chromium (VI) Removal from Aqueous Solutions by Ocimum americanum L. Seed Pods. Journal of Hazardous Materials, 161, 709713. http://dx.doi.org/10.1016/j.jhazmat.2008.04.031

[3] Layton, L. (2010) Probable Carcinogen Hexavalent Chromium Found in Drinking Water of 31 US Cities. The Washington Post, 20 December 2010.

[4] Park, D., Yun, Y., An, C.K. and Park, J.M. (2007) Kinetics of the Reduction of Hexavalent Chromium with the Brown Seaweed Colonia Biomass. Chemosphere, 66, 939-946. http://dx.doi.org/10.1016/j.chemosphere.2006.05.068

[5] Anderson, R.A. (1998) Chromium, Glucose Intolerance and Diabetes. Journal of the American College of Nutrition, 17, 548-555. http://dx.doi.org/10.1080/07315724.1998.10718802

[6] Berner, T.O., Murphy, M.M. and Slesinski, R. (2004) Determining the Safety of Chromium Tripicolinate for Addition to Foods as a Nutrient Supplement. Food and Chemical Toxicology, 42, 1029-1042. http://dx.doi.org/10.1016/j.fct.2004.02.015

[7] Fendorf, S.E. (1995) Surface Reactions of Chromium in Soils and Waters. Geoderma, 67, 55-71. http://dx.doi.org/10.1016/0016-7061(94)00062-F

[8] Sedlak, D.L. and Chan, P.G. (1997) Reduction of Hexavalent Chromium by Ferrous Iron. Geochimica et Cosmochimica Acta, 61, 2185-2192. http://dx.doi.org/10.1016/S0016-7037(97)00077-X

[9] Voelker, B.M. and Sedlak, D.L. (1995) Iron Photoreduction by Photo Produced Superoxide in Seawater. Marine Chemistry, 50, 93-102. http://dx.doi.org/10.1016/0304-4203(95)00029-Q

[10] Eary, L.E. and Rai, D. (1988) Chromate Removal from Aqueous Wastes by Reduction with Ferrous Ion. Environmental Science and Technology, 22, 972-977. http://dx.doi.org/10.1021/es00173a018

[11] Fendorf, S.E. and Li, G. (1996) Kinetics of Chromate Reduction by Ferrous Iron. Environmental Science and Technology, 30, 1614-1617. http://dx.doi.org/10.1021/es950618m

[12] Pettine, M., O’toe, L., Campanella, L., Millero, F.J. and Assino, R. (1998) The Reduction of Chromium (VI) by Iron (II) in Aqueous Solutions. Geochimica et Cosmochimica Acta, 62, 1509-1519. http://dx.doi.org/10.1016/S0016-7037(98)00086-6

[13] Buerge, I.J. and Hug, S.J. (1997) Kinetics and pH Dependence of Chromium (VI) Reduction by Iron (II). Environmen- 
tal Science and Technology, 31, 1426-1432. http://dx.doi.org/10.1021/es960672i

[14] Świetlik, R. (2002) Kinetic Study of Redox Processes of Chromium in Natural River Water. Polish Journal of Environmental Studies, 11, 441-447.

[15] Schlautman, M.A. and Han, I. (2001) Effects of pH and Dissolved Oxygen on the Reduction of Hexavalent Chromium by Dissolved Ferrous Iron in Poorly Buffered Aqueous Systems. Water Research, 35, 1534-1546. http://dx.doi.org/10.1016/S0043-1354(00)00408-5 
Scientific Research Publishing (SCIRP) is one of the largest Open Access journal publishers. It is currently publishing more than 200 open access, online, peer-reviewed journals covering a wide range of academic disciplines. SCIRP serves the worldwide academic communities and contributes to the progress and application of science with its publication.

Other selected journals from SCIRP are listed as below. Submit your manuscript to us via either submit@scirp.org or Online Submission Portal.
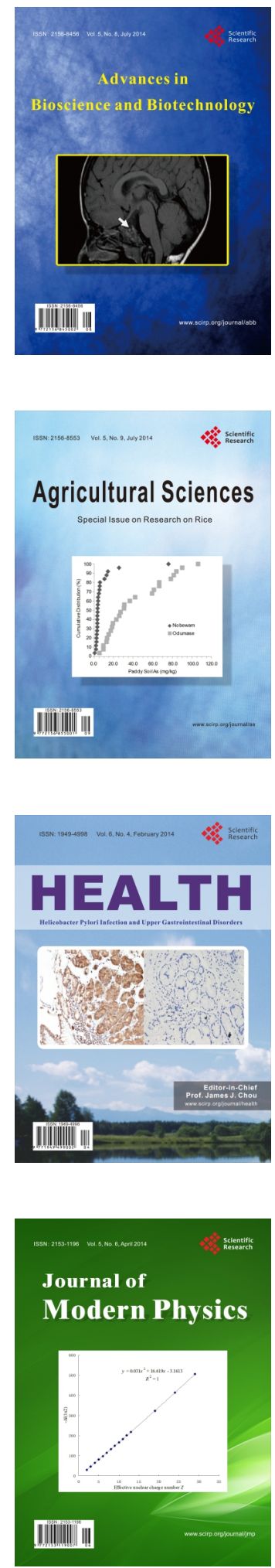
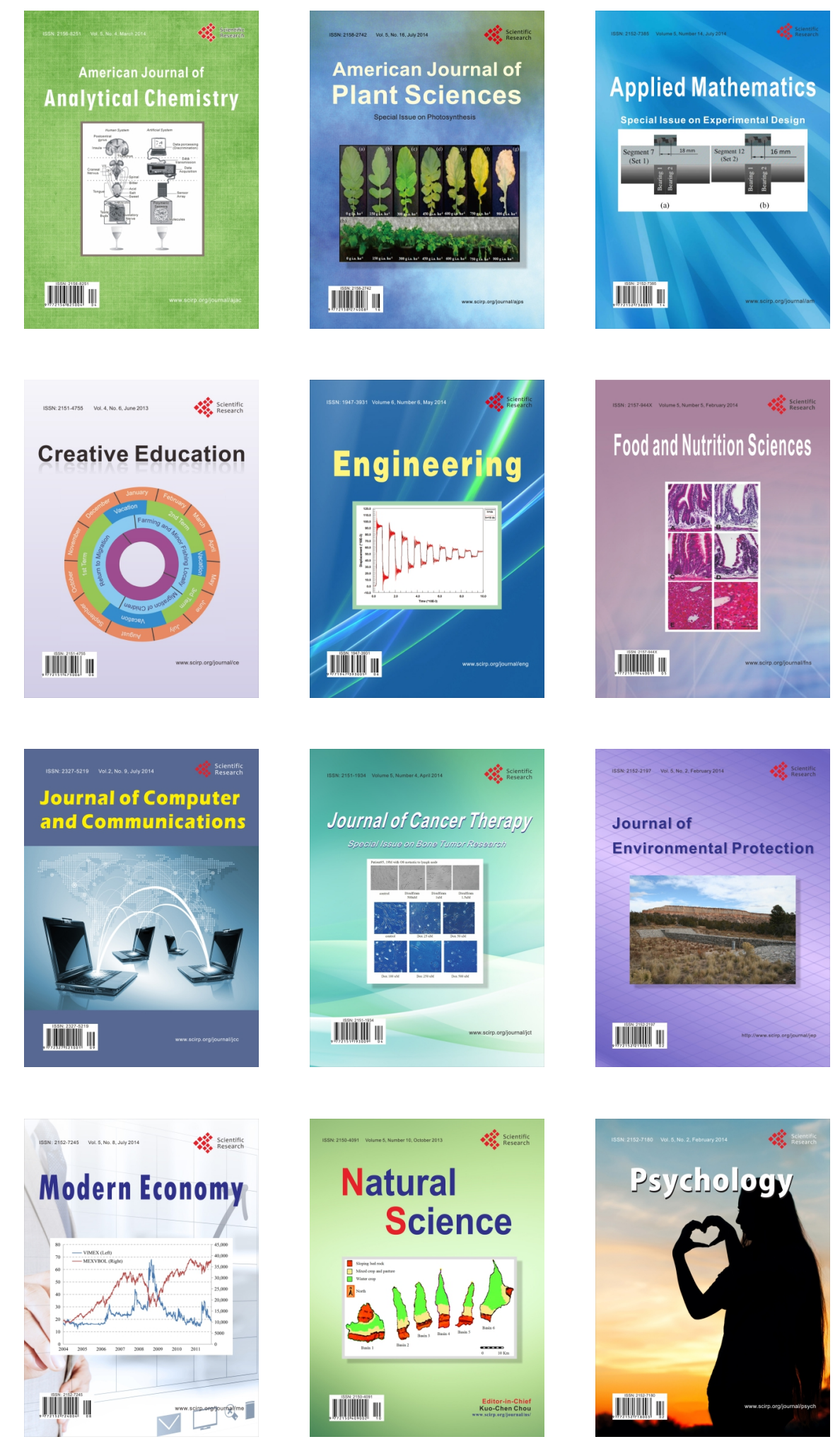